\title{
Organização coletiva e sementes crioulas: uma forma de luta e resistência pela identidade sociocultural quilombola na comunidade Sítio Veiga em Quixadá-CE
}

\author{
Fernanda lelpo da Cunha ${ }^{1}$, Luís Tomás Domingos ${ }^{2}$, Ana Maria Eugenio da Silva ${ }^{3}$, José Gerardo Vasconcelos ${ }^{4}$ \\ 1, 2, 3 Universidade da Integração Internacional da Lusofonia Afro-Brasileira - UNILAB. Mestrado Acadêmico em \\ Sociobiodiversidade e Tecnologias Sustentáveis (MASTS). Campos Aurora. Rua José Franco de Oliveira, s/n. Redenção - CE. \\ Brasil. ${ }^{4}$ Universidade Federal do Ceará - UFC. \\ Autor para correspondência/Author for correspondence: ferielpo@gmail.com
}

\begin{abstract}
RESUMO. O cultivo de sementes crioulas faz parte da sabedoria da herança ancestral, que pode ser contada desde o início da história da agricultura, sendo as comunidades tradicionais as grandes guardiãs desse patrimônio cultural, cujos ensinamentos transpõem a preservação de suas memórias, uma vez que chamam a atenção para a preservação da própria vida no planeta e das próximas gerações, em que a preservação do patrimônio genético dessas sementes garantirá a biodiversidade existente na Terra. Diante dessa realidade, o presente estudo tem como objetivo analisar como as formas de organização coletiva em torno do cultivo de sementes crioulas contribuem para a preservação da identidade sociocultural quilombola na comunidade de quilombo Sítio Veiga em Quixadá, no Ceará. A presente pesquisa é de cunho qualitativo, realizada in loco, cuja modalidade norteadora foi a etnográfica, com observação participante, métodos estes fundamentais para uma maior aproximação e interação com os sujeitos sociais da pesquisa e das ações inerentes ao cultivo de sementes crioulas.
\end{abstract}

Palavras-chave: Sementes Crioulas, Organização Coletiva, Quilombo. 


\title{
Collective organization and Creole seeds: a way of struggle and resistance for the Quilombola socio-cultural identity in the Sítio Veiga community in Quixada-Ceará
}

\begin{abstract}
The cultivation of Creole seeds is part of the wisdom of the ancestral legacy, which can be told since the beginning of the agriculture history, being the traditional communities the great guardians of this cultural heritage, whose teachings transpose the preservation of their memories, since they call attention to the preservation of life itself on the planet and of the next generations, where the preservation of the genetic heritage of these seeds will guarantee the biodiversity existing on Earth. Faced with this reality, this study aims to analyze how the ways of collective organization based on the cultivation of Creole seeds contribute to the preservation of the Quilombola socio-cultural identity in the quilombo community Sítio Veiga in the city of Quixadá, in Ceará state. This research has a qualitative nature, carried out in loco, whose guiding mode was ethnographic, with participant observation, methods that are fundamental for a greater approximation and interaction with the social subjects of the research and the actions inherent to the cultivation of Creole seeds.
\end{abstract}

Keywords: Creole Seeds, Collective Organization, Quilombo. 


\section{Organización colectiva y semillas criollas: una forma de luta $y$ resistencia por la identidad sociocultural Quilombola en la comunidad Sítio Veiga en Quixadá-CE}

RESUMEN. El cultivo de semillas criollas forma parte de la sabiduría proveniente de la herencia ancestral, que puede ser contada desde el comienzo de la historia de la agricultura, con comunidades tradicionales como grandes guardianes de ese patrimonio, cuyas enseñanzas van más allá de la preservación de su memoria, pues advierten para la preservación de la propia vida en el planeta y de las próximas generaciones, en que la preservación del patrimonio genético de esas semillas garantirá la biodiversidad existente en la Tierra. Ante esa realidad, este estudio objetiva analizar cómo las formas de organización colectiva sobre el cultivo de semillas criollas contribuyen en la preservación de la identidad sociocultural Quilombola en la comunidad de quilombo Sítio Veiga en Quixadá, en Ceará. Esta investigación es de tipo cualitativo, realizada in situ, de naturaleza etnográfica, con observación participante, métodos fundamentales para promover la aproximación e interacción con los sujetos sociales del estudio y de las acciones inherentes al cultivo de semillas criollas.

Palabras clave: Semillas Criollas, Organización Colectiva, Quilombo. 

forma de luta e resistência pela identidade sociocultural quilombola na comunidade Sítio Veiga em Quixadá-CE...

\section{Introdução}

Hoje as populações tradicionais são as grandes responsáveis por preservar técnicas e meios de cultivo, como as sementes crioulas nos espaços rurais. Todavia, desde o surgimento da agricultura moderna, do aprimoramento da mecanização e dos insumos agrícolas nos processos produtivos, atrelados à expansão das multinacionais e do agronegócio - que passaram a alterar o ácido desoxirribonucleico (DNA) natural das sementes através da engenharia genética, transformando-as em híbridas, transgênicas para fins comerciais - e à produtividade em grande escala, a agricultura tradicional e as sementes crioulas têm perdido cada vez mais espaço, sendo inclusive esquecidas pelo poder público.

Os resultados desse cenário se configuram pela própria realidade de exclusão social tanto do homem do campo quanto das comunidades tradicionais, que passaram a ser os maiores prejudicados, devido aos conflitos no campo, à acumulação das terras por parte dos grandes empresários e latifundiários, às migrações constantes das regiões Norte e Nordeste para áreas rurais escravizadas e à marginalização e preconceito das técnicas tradicionais, vistas pelo mercado capitalista como técnicas de menor valor, daí incompatíveis aos ideais de progresso e desenvolvimento propagada (Figueiredo et al., 2013).

Somada a essas questões, destaca-se ainda a realidade vivenciada pelas comunidades quilombolas que buscam o reconhecimento de seus territórios e posse de suas terras. Esses povos têm uma história de resistência e luta trazida pelas raízes africanas, sendo até hoje esse legado cultural mal interpretado pela sociedade, o que coloca em risco suas tradições, tais como o cultivo de sementes crioulas, constantemente ameaçado pelo mercado do agronegócio e suas indústrias de veneno.

Assim, com base nas questões acima suscitadas, surgiram nossos interesses em querer pesquisar, a partir das atividades do cultivo de sementes crioulas do quilombo Sítio Veiga, em Quixadá, Ceará, Brasil, como estas ações são socializadas, levando em consideração o lugar de vivência e os saberes repassados por seus ancestrais, sendo elaborado o seguinte objetivo a partir dessas inquietações: analisar como as formas de organização coletiva em torno do cultivo de sementes crioulas contribuem para a preservação da identidade sociocultural quilombola na comunidade de quilombo Sítio Veiga em Quixadá-CE.

A presente pesquisa ocorreu em caráter qualitativo, a qual, segundo Minayo (2002, p. 21-22), é uma pesquisa que “... 

forma de luta e resistência pela identidade sociocultural quilombola na comunidade Sítio Veiga em Quixadá-CE...

trabalha com dados que não podem ou não têm como serem medidos, como, por exemplo: crenças, valores, atitudes e situações". A referida autora enfatiza que esse tipo de abordagem é utilizado quando se busca compreender um determinado fenômeno na perspectiva dos indivíduos que o vivenciam. $\mathrm{O}$ estudo recorreu ainda à modalidade e revisão de literatura com análise bibliográfica, descrição etnográfica e observação participante in loco.

Os referidos métodos escolhidos se complementam em nossa pesquisa. Do método etnográfico cabe a relevância de compreender a realidade social das comunidades tradicionais, condutas, expressões culturais, modos de ser e viver singulares/peculiares, cujas descrições dos eventos e dos lugares por onde transitam esses sujeitos sociais precisam desse olhar mais cuidadoso do pesquisador, muitas vezes silencioso. “... O enfoque etnográfico intenta descrever a totalidade de um fenômeno (grupo social, aulas, festas populares, etc.) em profundidade e em seu âmbito natural, compreendê-lo desde o ponto de vista dos que estão implicados nele..." (López, 1999, p. 46). Portanto, esse método subsidiou a aproximação necessária com a comunidade Sítio Veiga, ao mesmo tempo em que nos permitiu descrever e experimentar suas experiências, pois "Tal método permite vivenciar a experiência deles, aprender deles e de suas experiências, explorar conceitos" (Bogdan et al., 1975 apud López, 1999, p. 46).

A pesquisa in loco ocorreu no período de junho a agosto de 2019, após a aprovação, autorização e determinação do Comitê de Ética em Pesquisa (Plataforma Brasil, Resolução no 466/2012), que trata e regulamenta as diretrizes e normas que envolvem seres humanos. As coletas das informações foram registradas em diário de campo, áudio e gravação devidamente autorizados pelos(as) participantes da pesquisa.

A população entrevistada conta com um quantitativo de 15 quilombolas maiores de 18 anos, que residem e moram no quilombo, que trabalham ou têm conhecimento no cultivo de sementes crioulas e que voluntariamente se dispuseram a responder à entrevista com perguntas previamente semiestruturadas. Definimos a amostra de acordo com a congruência ou a coincidência de opiniões contidas nas falas dos(as) entrevistados(as), bem como utilizamos nomes fictícios, elegendo nomenclatras de sementes crioulas para nos referir aos sujeitos que participaram deste estudo, tais como: 1) Fava Balinha; 2) Fava Espírito Santo; 3) Feijão Querentin; e 4) Milho Amarelo. Para garantir total anonimato, não mencionaremos o sexo e a idade dos(as) 
entrevistados(as), visto a proximidade entre eles(as) e a possibilidade de identificálos(as) dentro do quilombo, o que foi solicitado entre os sujeitos sociais da pesquisa.

Portanto, fica patente a relevância do presente estudo, que ocorreu pela procura sistemática de narrativas que fossem capazes de desvelar os sentimentos internalizados desses sujeitos sociais no que tange à própria identidade quilombola ao processo de organização coletiva em torno das sementes crioulas e aos aspectos de preservação e sustentabilidade ambiental, deixando registradas significativas contribuições aos legados acadêmico, social e cultural desses sujeitos sociais, como veremos adiante.

Do coletivo a terra, ao território e às sementes crioulas: um lugar para se organizar, pensar, lutar, resistir e continuar a existir

As bases de organização coletiva de quilombos no Brasil estabelecem uma forte influência dos povos africanos, especificamente os de origem bantu ${ }^{\mathrm{i}}$ trazidos da África e escravizados no Brasil (XVI-XVII), cuja relação estabelecida foi se firmando pelo sentimento de laços coletivos e de pertencimento étnico, uma base de formação política que se firmou na luta contra a escravatura e suas formas de opressão, consolidando-se mesmo após a abolição da escravatura como elemento de formação territorial, somadas à luta pela posse de seus territórios, um lugar de refúgio para os homens e mulheres continuarem lutando, organizando-se coletivamente (Munanga, 1996).

... a relação do quilombo brasileiro com o quilombo africano reafirma sua importância como forma de resistência ao escravismo. Nessa perspectiva, mais que um refúgio para os negros, os quilombos foram reunião de homens e mulheres que se negaram a viver sob o regime de escravidão e que desenvolviam laços de solidariedade e fraternidade na reconquista de sua dignidade. Assim, a ênfase na definição deve, então, ser posta sobre o binômio resistência e autonomia, e não sobre o ato da fuga. (Munanga, 2001 apud Silva \& Nascimento, 2012, p. 27).

Assim, foi na relação com a terra e o território que foram se consolidando as bases de organização coletiva nos quilombos brasileiros, fazendo da terra um lugar para pensar o grupo, suas expressões culturais, religiosas, artísticas e gastronômicas, os ensinamentos dos seus ancestrais, o cuidado com a agricultura, o cultivo de suas sementes crioulas, o que reflete todo o cuidado desses povos em manterem vivas suas tradições e as memórias de seus ancestrais, sendo estas repassadas entre gerações (Cunha et al., 2019).

Claro que entender o que seja quilombo e suas formas de organização 

forma de luta e resistência pela identidade sociocultural quilombola na comunidade Sítio Veiga em Quixadá-CE...

coletiva não é algo tão simples, levando-se em conta a própria negação nos processos históricos desses povos e as visões estereotipadas construídas e perpetuadas socialmente, cuja percepção distorcida deixou resquícios que perduram até hoje, século XXI, retratando os quilombolas como sendo fugitivos, isolados, habitantes das florestas, seres humanos selvagens, bandidos, dentre outras denominações, o que faz refletir as palavras de Fava Espírito Santo (2019):

Primeiro é preciso entender que o quilombo que se discute hoje é o quilombo do passado, né, o quilombo antigo, que não corresponde à nossa realidade, naquela perspectiva do negro como escravizado, do negro apanhando, do negro em sofrimento... O quilombo não está dentro de uma bolha, ele está dentro de um todo, e este todo... fortalece essa questão do negro... Não podemos aceitar o negro como se ele não fosse capaz, do negro como se não fosse um indivíduo, que vai ocupar os piores trabalhos; não digo os piores trabalhos, mas aqueles que requerem mais força, daquele estereótipo que foi criado no passado e que ainda perdura até hoje... Então, nós carregamos esses estereótipos do processo escravocrata em todos os espaços, né? É na escola, na saúde, no campo, na cidade..., e isso faz com que muitos não assumam sua identidade. Quem quer ser negro se ser negro para a sociedade é ser feio, é ser vergonhoso?

As palavras elucidadas trazem vários elementos e reflexões relevantes para desconstruir a imagem até então imposta sobre o quilombo, haja vista que não se pode pensar o(a) quilombola como um ser humano fora da sociedade, enclausurado(a) e refém do passado escravocrata. No quilombo existem formas de organização, processos de resistências e de lutas. Hoje os(as) quilombolas transitam por diversos espaços, não se restringindo unicamente ao quilombo, tais como universidades, movimentos sociais, associações comunitárias, o que faz refletir sobre uma nova compreensão do que seja quilombo na atualidade, suas formas de organização, que se interligam nesses espaços e em suas ações cotidianas, coadunando-se com as palavras de Leite (2000, p. 335):

Tudo isto se esclarece quando entra em cena a noção de quilombo como forma de organização, de luta, de espaço conquistado e mantido através de gerações. O quilombo, então, na atualidade, significa para esta parcela da sociedade brasileira, sobretudo um direito a ser reconhecido e não propriamente e apenas um passado a ser rememorado.

Logo, é preciso entender que os(as) remanescentes de quilombo têm raízes ancestrais, laços de coletividade e formas de organização coletiva presentes nos espaços políticos, que se entrelaçam às especificidades do seu modo de ser e viver, da ocupação de seus territórios e das lutas diárias para ocuparem também um lugar na sociedade; por se manterem livres; por 

forma de luta e resistência pela identidade sociocultural quilombola na comunidade Sítio Veiga em Quixadá-CE...

lutarem para serem reconhecidos(as) como cidadãos(ãs) de direitos.

E foi nessa trajetória de luta pela terra e pelo território que se destacou a aprovação da Lei das Terras de 1850, um marco na história da organização coletiva e política dos quilombos, consolidando o direito ao território como condição primordial à sua sobrevivência e posteriormente os inseriu nos debates sobre as questões da Reforma Agrária dos movimentos negros organizados. Uma luta cotidiana, que se reflete nos espaços políticos, de conquistas e reivindicações, trazendo mais uma vitória, que culminou com a aprovação do artigo 68 do Ato das Disposições Constitucionais Transitórias (ADCT) da Constituição Federal de 1988, que tornou obrigatórios o reconhecimento e a titulação dos territórios quilombolas (Monteiro, 2004).

Nos últimos 30 anos os descendentes de africanos, organizados em associações quilombolas, reivindicam $\mathrm{o}$ direito à permanência e ao reconhecimento legal da posse de suas terras ocupadas e cultivadas para moradia e sustento, bem como o livre exercício de suas práticas culturais, crenças e valores considerados em sua particularidade. (Leite, 2000 apud Monteiro \& Garcia, 2010, p. 154).

O atributo da resistência nos espaços de organização coletiva estabelece, portanto, as formas de luta na busca pela preservação do espaço conquistado e preservado por gerações, ao mesmo tempo em que envolve a relação com o território, sendo este o espaço de referência para a construção da própria identidade quilombola, mais precisamente um espaço físico-material, mas também político, econômico, social e simbólico (Silva \& Nascimento, 2012). "Se hoje existem territórios quilombolas é porque em um momento histórico dado um grupo se posicionou, aproveitando uma correlação de forças políticas favoráveis, e instituiu um direito que fez multiplicar os sujeitos sociais e as disputas territoriais" (Silva \& Nascimento, 2012, p. 35).

Vale destacar ainda que a constituição da identidade quilombola envolve a própria necessidade de luta, posto que, quando uma comunidade quilombola se organiza coletivamente e reivindica seus direitos, por manter viva a reminiscência de seus ancestrais, quando ela também luta para se territorializar, está exercendo um novo olhar sobre a sociedade, ou seja, sobre aquele indivíduo que lhe foi negado transitar como cidadão(ã) de direito, de ser incluído(a) socialmente, estabelecendo, assim, uma nova territorialidade (Silva \& Nascimento, 2012).

Dito isso, territorializar significa poder, autonomia, possibilidade de 
ascensão, superação das vulnerabilidades sociais, uma forma de se colocar no mundo, estabelecendo a conexão com seus ancestrais, com seus rituais sagrados, com o exercício de cidadania, com os aspectos materiais e simbólicos da vida.

Partindo dessas premissas, é preciso dar vez e voz aos povos quilombolas, situá-los como sujeitos de suas próprias histórias, deixar que possam falar por si, pois suas representações coletivas estão fincadas no chão, na terra, nos seus processos organizativos, haja vista que no quilombo existem associações que também os representam e que estão dentro dos processos de tomadas de decisão dentro de seus territórios, repercutindo significativamente nos aspectos de organização política, socioeconômica e cultural das conquistas almejadas, como veremos nas palavras de Feijão Balinha (2019):

Nosso quilombo se reúne para tomar decisões. Chamamos a comunidade para participar, alguns vão, outros não gostam de participar, mas o convite é feito... Olha, conseguimos muitas coisas pela associação, como nossas cisternas, água nas casas, a própria casa de sementes foi decisão nossa, os vários cursos, a própria entrada dos jovens na Unilab [Universidade da Integração Internacional da Lusofonia AfroBrasileira], o próprio reconhecimento do nosso território, que ninguém tira, mas conseguimos com nossa luta, com o apoio de todos da associação; em 2009, fomos reconhecidos como comunidade quilombola, agora só está faltando o presidente assinar sobre nossa posse... Acho que até mesmo o respeito da sociedade ganhamos mais, pois todos perguntam como conseguimos tanta coisa; querem até se juntar a nós... Todos deveriam participar, compreender a importância da gente se reunir para melhorar nossa situação. Com união é mais fácil conseguirmos as coisas.

Assim, percebe-se que da relação com a terra foi sendo estabelecida a organização política em torno do território, da posse da terra, do direito de continuar cultivando suas sementes e celebrando seus rituais em seu solo sagrado, cujo palco dessas disputas pela legitimação de seus direitos se revela como suas bandeiras de lutas, palco de reivindicação e resistência.

Nessa óptica, é mister considerar a forte representação do autorreconhecimento e a certificação para a comunidade quilombola Sítio Veiga, no ano de 2009, concedidos pela Fundação Palmares ${ }^{\mathrm{ii}}$, conquistas capazes de legitimar seu reconhecimento como remanescente de quilombos, mas que também abrem os caminhos a inclusão social, ao direito às políticas públicas afirmativas e aos programas sociais, passando também a dar visibilidade à identidade quilombola desses sujeitos sociais. Uma visibilidade que, para os sujeitos sociais da pesquisa, passou a ressignificar sua imagem na sociedade como sujeitos sociais de direitos, o que traz 
à tona a própria singularidade dessa comunidade - elemento este essencial ao pertencimento e recorte étnico-racial do que é ser quilombola, cujas raízes estão fincadas na terra, nas sementes crioulas, nas suas formas de organização e nas reminiscências dos saberes repassados por seus ancestrais.

Os(As) que lá residem vivem da agricultura de subsistência, sendo a principal renda advinda da terra, em que a atividade ocorre pela socialização dos saberes repassados por seus ancestrais em seus roçados, como o plantio de sementes crioulas, tais como: milho, feijão, fava, melancia, maxixe, jerimum, pepino, etc. Portanto, além da produção oriunda dos roçados, há também uma pequena parte da produção advinda dos quintais produtivos, por exemplo: frutas, verduras, plantas medicinais e criações de animais de pequeno porte. Quase toda a produção é destinada ao consumo das famílias, e o pouco excedente, quando sobra, as famílias comercializam para outras comunidades ou o vendem na própria comunidade ou no entorno.

Desse modo, temos ainda as fortes representações das diversas variedades de sementes crioulas para a manutenção e a preservação dos(as) quilombolas e dos ensinamentos perpetuados entre as gerações. Pensando nesse fortalecimento das sementes crioulas e depois de muitos debates sobre a importância delas, os(as) quilombolas do Sítio Veiga construíram, de forma organizativa e coletiva, uma casa de sementes mantida pelas famílias que ali residem, cujo nome foi atribuído em homenagem ao fundador da comunidade, Francisco Ribeiro Bessa, conhecido carinhosamente como Pai Xigano ${ }^{\text {iii }}$, sendo o referido nome repleto de significados sócio-históricos.

Embora havendo casas de sementes nas unidades familiares quilombolas, havia uma necessidade de um espaço coletivo, objetivando as discussões sobre a importância, assim como sobre as diversidades e variedades de sementes. Trazer de volta as sementes perdidas era uma das metas da casa de sementes Pai Xigano. A partir daí, foi feito um encontro com as famílias para realizar um levantamento das sementes plantadas em nossos territórios pelos nossos ancestrais e pelos protagonistas de hoje, crianças, mulheres e homens quilombolas do Veiga. E foi de intensas discussões dentro e fora do quilombo que brota e nasce a casa de sementes. Na ocasião foi escolhido o nome da primeira semente oriunda de Pau dos Ferros, Rio Grande do Norte: esta semente, conhecida como Pai Xigano, foi plantada, brotando e vingando umas variedades de outras sementes, cuja resistência vem de longe, muito longe; as marcas de resistência estão impregnadas no sangue, na alma das famílias e das sementes de Pai Xigano. Ao falar da casa de sementes Pai Xigano, automaticamente se está falando da luta, da resistência, da cultura dos que antecederam e também das famílias quilombolas que continuam a resistir para existir... (Fava Espírito Santo, 2019). 

forma de luta e resistência pela identidade sociocultural quilombola na comunidade Sitio Veiga em Quixadá-CE...

Portanto, a casa de sementes é história, memória, compromisso, resistência, ensinamento, aprendizado, cultura, enfim, uma vasta possibilidade de deslocamentos através do tempo e do espaço. Nessa caminhada, houve a parceria com o Centro de Pesquisa e Assessoria Esplar $^{\text {iv }}$, cujo apoio e assessoria foram de grande relevância, por meio do projeto Sementes do Semiárido, que fez aflorar ainda mais as discussões sobre o espaço coletivo de sementes. A construção da casa de sementes ocorreu de maneira coletiva, em que a consciência ambiental proposta nessa parceria contribuiu para despertar o valor das sementes e da biodiversidade embutido no próprio cultivo, de sua importância para a qualidade de vida e saúde humana, bem como para a preservação ambiental e o futuro das próximas gerações.

O papel da assessoria do Esplar também foi essencial no resgate de algumas sementes até então perdidas, fomentando o intercâmbio entre as diversas comunidades tradicionais a fim de aproximá-las nesse resgate e troca de experiências. A comunidade, a partir desse projeto, pôde identificar suas sementes tradicionais, dando um significado ao resgate de suas memórias, dentre as quais se destacam: feijão pingo de ouro, feijão amarelo, feijão do Everardo, fava espírito santo, feijão roxo, milho ibra, milho cateta, milho vermelho, sendo essas algumas das espécies cultivadas no Sítio Veiga desde sua origem, ficando agora guardadas na casa de sementes Pai Xigano. Estabelece-se, com isso, maior visibilidade ao quilombo, além de lhe propiciar maior autonomia, pois seus membros passam a não mais depender unicamente das sementes do governo para plantar. Com relação às sementes distribuídas pelo governo, as famílias do quilombo as consideram inadequadas, por serem contaminadas por agrotóxicos, trazendo sérios prejuízos à saúde e contaminando o solo. Desse modo, suas sementes são guardadas individualmente em cada casa, bem como armazenadas e estocadas na casa de sementes Pai Xigano, como veremos adiante:
... quando construímos a casa de sementes Pai Xigano, estávamos preocupados, porque tem um projeto do agronegócio desde o golpe ${ }^{\mathrm{v}}$ de proibir as sementes crioulas e a circulação das sementes. A própria Bayer é responsável por produzir o veneno, mas a casa de semente já vem com uma discussão bem antes disso para não usar em nossas plantações, ... exatamente para não perder as sementes como a gente perdeu a semente do quiabo e de tantas outras sementes. Isso foi muito difícil a gente implantar dentro da comunidade. (Feijão Balinha, 2019).

Desse modo, a memória ancestral de Pai Xigano se articula a diversos aspectos das atividades do cultivo de sementes 

forma de luta e resistência pela identidade sociocultural quilombola na comunidade Sítio Veiga em Quixadá-CE...

crioulas que se complementam, por exemplo: a agricultura familiar; a valorização e a luta pelo território e pela forma de organização das famílias que ali residem; o cuidado com a indústria do veneno em suas plantações; e a forte relação com a terra e com o meio ambiente.

Como pudemos verificar, a construção da organização coletiva em torno do cultivo de sementes crioulas perpassa por diversos aspectos socioculturais, políticos e econômicos capazes de ressignificar suas relações coletivas, os laços de pertencimentos étnico-raciais e a identidade quilombola. Uma organização coletiva que luta pela vida e pela existência e que também marca a resistência impregnada na alma dessas famílias e de suas sementes para continuarem a ter o direito de viver e existir, de preservar suas memórias ancestrais, ensinamentos, aprendizados, culturas e cada conquista em torno de seus territórios, das terras, sendo esta uma luta constante pela construção do território/terra almejado(a) por eles(as).

A herança ancestral e cultivo de sementes crioulas: um conhecimento necessário à preservação das futuras gerações

Segundo Trindade (2006), a denominação de sementes crioulas se caracteriza por aquelas que não sofreram modificações genéticas em sua forma natural ou original. Geralmente são sementes nativas e peculiares de determinada região, repassadas de uma geração a outra, sendo cultivadas por comunidades tradicionais, especialmente as de características quilombolas, as indígenas, as ribeirinhas, as caboclas, etc.

$\mathrm{Na}$ comunidade Sítio Veiga, a denominação de sementes crioulas estabelece uma conexão muito forte entre os saberes ancestrais e a própria preservação das espécies naturais das sementes, haja vista o fato de que as sementes crioulas aparecem nas comunidades tradicionais como uma forma de manter a tradição de repasse de conhecimento entre gerações, o que faz garantir a própria subsistência local. Estabelece uma relação de interação com a natureza sem tantos impactos ambientais, baseada no próprio alimento e na comercialização sem excessos, opondo-se aos princípios de lucratividade e de consumo exacerbado do modelo capitalista, como afirma o(a) entrevistado(a) adiante:

As sementes serão para plantar, produzir e sustentar as futuras gerações, e esses grãos vão ser também para sustentar naquele momento. Esses grãos nesse momento vão servir de alimentação humana e animal, porque no quilombo nós trabalhamos com 

forma de luta e resistência pela identidade sociocultural quilombola na comunidade Sitio Veiga em Quixadá-CE...

agricultura de subsistência. O que é isso? Nós trabalhamos para o consumo. Essas sementes não são vendidas, escoadas. Raramente 0 excedente é escoado; geralmente fica no próprio quilombo, pois todo mundo no quilombo cria galinhas, porcos; jumentos também servem para eles se alimentarem... E, como nós também não temos o território ainda em nossas mãos, então nossos espaços são muito pequenos para produzir. (Fava Espírito Santo, 2019).

A sabedoria ancestral envolve $\mathrm{o}$ conhecimento oralmente perpassado pelas práticas agrícolas das comunidades tradicionais, cujo conhecimento das plantas, da terra e de todas suas propriedades estabelece a conexão entre o passado e o presente para garantir a existência da vida e o futuro das próximas gerações.

... um velho conhecerá não apenas a ciência das plantas (as propriedades boas ou más de cada planta), mas também a 'ciência das terras' (as propriedades agrícolas ou medicinais dos diferentes tipos de solo), a 'ciência das águas', astronomia, cosmogonia, psicologia, etc. Trata-se de uma ciência da vida, cujos conhecimentos sempre podem favorecer uma utilização prática. (Bâ Hampâté, 2010, p. 167).

Esse legado deixado pela herança ancestral permanece vivo como forma de resistência das famílias quilombolas do Sítio Veiga, ressignificando as relações com a terra e os aspectos de organização, cuja forte influência dos ensinamentos ancestrais ocorre basicamente na agricultura de subsistência, ou seja, essas famílias dependem praticamente da terra para a sua sobrevivência, visto que é a partir dela que se reúnem e se organizam econômica, política, social e culturalmente, retirando da terra sua alimentação e a de seus animais, bem como os remédios usados por muitos; até mesmo o próprio ritual religioso praticado depende da terra, tal como a dança de São Gonçalo ${ }^{\text {vi }}$ e as 12 sementes crioulas utilizadas no ritual, fortalecendo os laços culturais de caráter ancestral, repassados entre gerações em torno das sementes crioulas e da espiritualidade, o que faz lembrar ainda as próprias palavras de Fava Espírito Santo (2019):

Não tem como você falar de quilombo sem falar das sementes crioulas. Não tem como você falar de quilombo sem você falar da importância do território, sobre a importância da dança de São Gonçalo... as jornadas da dança de São Gonçalo, que são 12 jornadas contadas por sementes, e são 12 sementes que são colocadas. $\mathrm{O}$ mestre de cultura é o tio Joaquim; ele pega 12 sementes - contam essas sementes antes da dança - e passa para o bolso do Oswaldo, que é um dos membros do grupo, e a cada jornada uma semente é devolvida para o mestre e colocada no bolso, então, de vez em quando, ele vai lá e diz: 'Olha, nós já tiramos cinco jornadas'... A dança é uma forma de celebrar, é um momento muito místico, de memória, de compromisso, de fortalecimento da identidade e de construção de novas 

forma de luta e resistência pela identidade sociocultural quilombola na comunidade Sitio Veiga em Quixadá-CE...

amizades... A dança ela é de extrema importância para as relações sociais, porque ali não estão somente os quilombolas, mas vêm pessoas de diversos lugares, e a gente vai se fortalecendo, se conhecendo. Cada estrofe que é cantada fala um pouco do nosso cotidiano... das nossas dificuldades.

Cabe ressaltar que há uma casa de sementes individual dentro das moradias de todos(as) os(as) que lá vivem, ou seja, uma unidade individual familiar, cujo cuidado nesse espaço é manter os costumes antigos de preservação das espécies próximas de seus guardiões, de seu cotidiano e dinâmica familiar. Esse costume vem atravessando gerações como modo de garantia de manutenção de suas sementes, de suas vidas e das futuras gerações, ao mesmo tempo também se estende coletivamente a outros espaços, garantindo a troca de conhecimento e de experiência entre eles(as), fortalecendo, assim, os laços de coletividade e de solidariedade, tão importantes à essência de ser e de viver em comunhão.

A manutenção de todos os rituais repassados pelos(as) ancestrais que incidem sobre as sementes crioulas ocorre ao entrarem e ao saírem de suas casas, sendo realizada pelos membros da própria família, dos mais jovens aos mais velhos, podendo também ter a contribuição de outras famílias quilombolas como extensão familiar comunitária. Desse modo, foi dos ensinamentos de seus ancestrais que trabalhavam e viviam da agricultura que foram sendo fomentados no Sítio Veiga o respeito e o cuidado com a terra e as sementes crioulas, perpertuados de uma geração à outra, mantendo-se o hábito não só de plantar as sementes, mas de respeitar cada ciclo da terra e da semente, ou seja, o tempo de plantar, o tempo de colher, o que colher para comer e o que guardar para as próximas plantações, pensando-se nas gerações subsequentes. Isso se reflete nas palavras de Domingos (2011, p. 9):

O Ancestral fundador de uma comunidade, aldeia, é considerado como aquele que estabeleceu a primeira aliança com as entidades divinas e tutelares da Terra. Esse Antepassado nascido da Terra pela mitologia é considerado o seu fundador. Ele transmite sua função de uma maneira hereditária aos possíveis 'chefes da terra', que usufruem de certos poderes sobre os outros homens em função da autoridade que detêm sobre o solo.

Assim, durante todo o ano, a colheita segue o ritmo de abastecer o consumo próprio, separando-se e estocando-se as melhores sementes em garrafas PETs e tambores metálicos ou plásticos, que podem ser armazenadas por até cinco anos, dependendo da espécie e da forma de armazenamento. Lá se guardam as sementes, separando-se cuidadosamente e socializando suas formas de cultivo e plantio de forma minuciosa, respeitosa e 

forma de luta e resistência pela identidade sociocultural quilombola na comunidade Sítio Veiga em Quixadá-CE...

cuidadosa, como veremos na fala de Milho

Amarelo (2019):

Até hoje nosso pai tem o hábito de plantar. Por exemplo, o milho ele vai selecionando aquelas espigas de milho, ele vai debulhando até a metade da espiga e deixa só a ponta, e aquele milho ali é o milho de planta, que ele guarda; o feijão, do mesmo jeito, vai colhendo as vagens, aquelas mais formosas, mais bonitas, e vai guardando dentro de uma garrafa de plástico ou qualquer outra vasilha de plástico, e assim vai passando de geração a geração. Mesmo hoje tendo a casa de sementes, que é o local onde guardamos muitas espécies, a gente também não perde o hábito de guardar em casa, em nossas garrafas e tambores, igual no nosso passado; a gente não consegue arrancar essas raízes e nunca vamos conseguir, porque é um hábito que aprendemos, e a gente já começa desde cedo a guardar as garrafas para na época da colheita guardar nossas sementes.

As sementes crioulas surgem como uma possibilidade de as comunidades tradicionais produzirem o seu próprio alimento sem tantos impactos negativos ao meio ambiente. Essa técnica tem a compreensão de que, ao respeitar cada fase e ciclo da terra e das sementes, é preciso conhecer as particularidades do próprio clima, da vegetação em seu entorno, da própria geografia do local, bem como o preparo correto e natural da terra, uma vez que há o tempo de plantar e o tempo de colher, o que não poderá jamais alterar ou estimular forçadamente sua produtividade,

\author{
principalmente com agrotóxicos e \\ fertilizantes.
}

Um aspecto relevante na definição dessas culturas tradicionais é a existência de sistema de manejo dos recursos naturais marcados pelo respeito aos ciclos naturais e pela sua exploração dentro da capacidade de recuperação das espécies de animais e plantas utilizadas. Esses sistemas tradicionais de manejo não são somente formas de exploração econômica dos recursos naturais, mas revelam a existência de um complexo de conhecimentos adquiridos pela tradição herdada dos mais velhos, por intermédio de mitos e símbolos que levam à manutenção e ao uso sustentado dos ecossistemas naturais. (Diegues et al., 1999, p. 30).

Por serem originais, as sementes crioulas não têm nenhum tipo de alteração no seu DNA, o que as torna únicas, $100 \%$ naturais, ao contrário das transgênicas e das híbridas, que sofreram modificações genéticas pela biotecnologia para fins comerciais, com produtividade exacerbada, em grande escala. $\mathrm{O}$ respeito e a preservação das sementes crioulas constituem um dos elementos principais realizados pelas comunidades tradicionais, o que garantirá a originalidade de suas espécies e sua perpetuação às futuras gerações. O processo aqui também é coletivo, organizativo, com um viés comunitário, com trocas de experiências, no sentido de resgatar e perpetuar suas espécies, tanto no âmbito local como também no âmbito das mais diversas e 
variadas comunidades tradicionais, como pontua Fava Espírito Santo (2019):

É uma semente que é cuidada, que é selecionada, essa semente ela passa nas mãos de todo mundo. Olha como isso é bacana: essa semente, ao ser plantada, ela passa nas mãos de muita gente nesse processo de cuidado, de limpar; mais uma vez vai um monte de pessoas para fazer parte desse processo, é um processo coletivo... O que eu chamo de coletivo, porque lá os trabalhadores, os agricultores, eles não têm como pagar diária, então eles trocam os dias. Então, essas sementes são construídas em um processo organizativo e, quando a galera está ali limpando o mato ou plantando, está falando do seu dia a dia, está planejando, está falando do passado. Então, falar de sementes crioulas é ancestralidade, é manter vivas nossas memórias. Se você olha e começa a analisar a história da semente crioula, não olha para sementes como só uma semente, mas como uma vida.

Assim, temos no quilombo Sítio Veiga uma atividade agrícola que, segundo os(as) entrevistados(as), respeita o meio ambiente e todas as etapas de plantio das sementes crioulas, sendo livres de agrotóxicos, fertilizantes, adubos, algo semelhante, consoante as palavras de Fava Espírito Santo (2019), a um "parto natural", ao contrário das sementes do governo, que o(a) entrevistado(a) acima mencionado(a) avalia como sendo algo forçado, pior do que um "parto cesariano", como veremos em suas palavras à frente:

... para produzir mais rápido, eles jogam um monte de nutrientes, para que essa planta cresça... Então, eu pego todas essas sementes que sofreram todas essas agressões... é bem mais bruto do que um parto cesáreo, porque o parto cesáreo é quando a mulher não tem passagem, não tem como a criança nascer. Mas, diferentemente do parto forçado, você tem como produzir sem precisar fazer forçação de barra, sem usar veneno, fertilizante, essas coisas que considero uma forçação desnecessária. Então, eu pego essa semente que está altamente sofrida e trago para cá para o quilombo; essa semente vai nascer, ela vai produzir, mas ela não vai nascer nem vai produzir na mesma proporção daquelas sementes que estão conosco e que são totalmente naturais. (Fava Espírito Santo, 2019).

Diante do exposto, os conhecimentos ancestrais no cultivo de sementes crioulas têm uma preocupação em manter vivas a tradição e a própria memória de seus ancestrais, repercutindo em uma alimentação mais saudável e livre de venenos, contribuindo para a preservação da vida no planeta, especialmente das próximas gerações, bem como dos conhecimentos que poderão ser herdados por esses sujeitos sociais.

\section{A negação das terras quilombolas: uma ameaça aos conhecimentos ancestrais e ao cultivo das sementes crioulas}

Com o advento do processo de desenvolvimento e modernização da década de 1970, o modelo tecnológico da Revolução Verde, após a Segunda Guerra Mundial, trouxe diversas mudanças às 
técnicas rudimentares que predominavam no campo, devido à implementação das novas tecnologias, alterando a relação capital/trabalho e consequentemente mudando as estruturas social e econômica dessas famílias, caracterizadas pelo êxodo rural, a substituição das sementes nativas (crioulas) pelas de espécie híbrida, transgênica e orgânica, o uso desenfreado de agrotóxicos e pesticidas artificiais nas plantações, levando os vários conhecimentos e técnicas das comunidades tradicionais e rurais a se perderem, a se tornarem excluídos ou dependentes dos novos pacotes tecnológicos (Carvalho, 2003), o que faz consubstanciar as palavras de Feijão Balinha (2019):

O governo não dá nenhum apoio para nossas sementes, apenas faz esses empréstimos das sementes envenenadas... Tenho medo que esse hábito acabe, pois a nova geração com certeza está desmotivada, porque o retorno é muito pouco e deixa qualquer pessoa desmotivada, até mesmo nós, que já somos mais velhos; por exemplo, no caso do meu pai, que já nasceu e se criou na agricultura, ele mesmo está muito desmotivado com a agricultura, aí os nossos filhos ficam muito desmotivados mesmo. Não temos apoio do governo de jeito nenhum; até o seguro-safra estamos perdendo; no ano passado não tivemos o seguro e esse ano ninguém fala, aí nós só ficamos no prejuízo o tempo todo, só temos perdas. Neste ano tivemos pouquíssimos legumes e imagine isso para uma família grande, não dá; o legume não vai dar; uma saca de feijão também não dá; onde tem pessoas aqui que são dez pessoas em uma casa não dá.

Tudo isso leva muitos desses sujeitos sociais a migrarem para outras cidades, a se distanciarem de seus entes queridos, de sua cultura local, uma vez que precisam garantir a sua sobrevivência e a de seus familiares, como aconteceu com Feijão Querentin (2019):

$\mathrm{Eu}$ fui para São Paulo pela necessidade mesmo, precisava ajudar minha família. Foi difícil, viu... Cheguei lá, me bateu uma saudade tão grande da tranquilidade daqui, do mato que eu gosto. Quando eu estava em São Paulo, só vivia gripado; uma vez lá eu peguei sinusite, eu trabalhei em câmara fria, um frigorífico, e eu trabalhei lá dentro mesmo da câmara fria, e tinha que ser com a porta fechada, aí dava aquela dor de cabeça; depois que eu voltei para cá, graças a Deus não tive mais nada.

As comunidades tradicionais e os saberes populares são vistos como entraves ao processo de desenvolvimento capitalista neoliberal, em que os meios de comunicação de massa os propagam como sendo incompatíveis aos ideais do mundo moderno, como pertencentes a uma cultura de menor valor e com técnicas sem comprovação científica, incompatíveis aos postulados de desenvolvimento e de progresso, tal como enfatiza Carvalho (2003, p. 10):

As iniciativas neoliberais
hegemônicas nas rociedades
ocidentais têm conseguido, através


das tentativas insanas de apagar o passado desses povos e dessas populações, rejeitar não apenas as suas culturas, mas com elas também os meios de produção utilizados como os saberes populares, os sítios ecológicos e as sementes 'varietais'. Territórios que foram diferenciados num convívio harmonioso com a natureza e vivenciados por inúmeras gerações, como aqueles dos povos indígenas e das populações camponesas, foram e continuam sendo negados e desconstruídos.

O apelo aos moldes modernos de desenvolvimento da agricultura tem a ganância dos países desenvolvidos, cuja exploração dos territórios subdesenvolvidos visa à ampliação do comércio internacional e às suas multinacionais espalhadas pelo mundo, um modelo que fomenta o agronegócio, a exploração das áreas nativas e das espécies preservadas por territórios tradicionais. Dito isso, as grandes multinacionais a serviço do grande capital já vêm intervindo em tecnologia de ponta, utilizando-se da biotecnologia e da manipulação da genética das sementes híbridas, das transgênicas, das orgânicas, na perspectiva de fins comerciais, como afirma Carvalho (2003, p. 9): “A partir dos interesses privados das grandes corporações capitalistas e do estabelecimento das normas legais para o patenteamento da propriedade, as sementes tornam-se um negócio".
O modelo acima objetiva, portanto, não só explorar os territórios quilombolas, disseminando e estimulando a indústria do veneno nas sementes fornecidas pelo governo com a liberação dos transgênicos pelo Brasil, o que compromete o próprio solo onde são plantadas também as sementes crioulas, modelo esse que, ao mesmo tempo, incentiva as queimadas e faz com que haja mortes e assassinatos das populações tradicionais em torno da posse da terra. Um conflito que se atrela à busca pela apropriação também das sementes crioulas, ou seja, patenteá-las, colocando em risco não só a manutenção da biodiversidade local como também nutricionalmente a qualidade de vida das pessoas e animais, a existência da vida quilombola e o próprio legado histórico e cultural que essas sementes representam.

O controle oligopolista das sementes não começa pelo patenteamento das novas variedades, híbridas e ou transgênicas, produzidas por instituições privadas e/ou públicas, sob o controle privado. $\mathrm{O}$ eixo central do controle das sementes pelos grandes grupos econômicos da biotecnologia se dá de maneira sutil, seja com a substituição gradativa das sementes crioulas, seja pelo seu 'esquecimento' ideológico, ambos induzidos pela propaganda comercial e pelas exigências das políticas públicas, em especial do crédito rural subsidiado e do seguro agrícola. (Carvalho, 2006 apud Barbosa et al., 2013, p. 378). 

forma de luta e resistência pela identidade sociocultural quilombola na comunidade Sitio Veiga em Quixadá-CE...

Nesse contexto, temos ainda as formas de sentimentos e atitudes ora valorizadas pelo modelo neoliberal, cujo slogan da modernidade é sinônimo de ciência e tecnologia em prol do lucro, da individualidade, da competição, do descaso público, assumidos como valores éticos, segundo Carvalho (2003). Tal realidade faz refletir o teor do documentário da Revista Carta Capital (2019), "Manifesto", que avalia as ações do governo e as iniciativas do agronegócio como sinônimos de desenvolvimento para o Brasil, slogan no cenário atual do governo Bolsonaro e seus discursos antiambientalistas, que visam a flexibilizar áreas para o desmatamento nas áreas de preservação ambiental, o que levou a um aumento considerável de queimadas no seu primeiro ano de mandato, somando-se aos seus discursos contra o aumento de demarcação das terras indígenas e quilombolas e contra a ampliação de reservas no Brasil, como enfatiza Fava Espírito Santo (2019):

O agronegócio é uma desgraça essa ambição. Por que qual a intenção do agronegócio? O agronegócio tira as sementes crioulas de nossas mãos, porque tirar as sementes crioulas de nossas mãos é tirar nossa autonomia, é tirar nossa própria vida, porque, assim que chove, a gente tem as sementes e vai lá e planta; como a gente vive em uma região de semiárido, ora chove, ora não chove, então nós temos que plantar nas primeiras chuvas. O meu avô dizia assim: 'Choveu, plantou; nasceu, limpou', e aí continua o outro processo. E, com essas sementes do governo..., elas chegam muito tarde, então muitos agricultores hoje o que fazem: eles deixam de produzir porque eles ficam esperando essas sementes, porque perderam o próprio hábito de guardar. As sementes crioulas você pode guardar por até dois anos ou mais, já as do governo não, porque você não sabe da procedência. As sementes que você guardou você sabe a procedência, o período que você guardou, de onde foi que elas saíram, de onde foi que elas vieram. E uma outra coisa que eu acho muito bacana nas sementes crioulas é que, por exemplo, eu tenho três tipos de milho, o que mais vende é o amarelinho, mas, como a gente não planta pensando em venda, então esse milho se mistura aos outros, aí eu tenho aqui os três tipos de milho, um desses é o mais cobiçado, mas, na hora de trocar, não importa, entendeu a troca? As trocas que eram feitas nas comunidades primitivas de que não importa se é mais caro ou mais barato, pois você não precisa me pagar, entendeu? Eu chego lá no tio Antônio, na Nésia: 'Me arranja aquela semente lá para plantar', ela me dá. Então, isso é muito bacana. Então, hoje algumas pessoas utilizam veneno, que não é o correto.

De acordo com Souza e Chaveiro (2018), o grande problema que envolve o agronegócio diz respeito às formas desiguais com que as terras são proporcionalmente apropriadas pelos grandes latifundiários e os grupos que os apoiam, cujo uso das terras, que deveriam ser bens comuns, não articula $\mathrm{o}$ desenvolvimento econômico à justiça social. Isso se torna uma ameaça às formas de vida existentes, sem se falar nas áreas 

forma de luta e resistência pela identidade sociocultural quilombola na comunidade Sítio Veiga em Quixadá-CE...

inteiras devastadas pelas queimadas, pelos agrotóxicos, deixando as terras improdutivas, comprometendo a biodiversidade, interferindo na saúde e na qualidade de vida das pessoas e afetando o futuro das gerações futuras.

Em relação ao agronegócio e ao sistema produtivo habitualmente empregado, as injustiças podem referir-se à concentração de terra e ao uso de bens comuns como a água e o solo, bem como também ao efeito dispersivo de insumos e resíduos. As diferentes reações a essas injustiças, ainda que de forma desproporcional (dadas as diferenças de poder econômico e político entre os grupos envolvidos), é o que poderá caracterizar uma situação de conflito, ressaltando o aspecto dialético do tema. Pode-se dizer que a aliança entre Estado, latifundiários e demais agentes vinculados ao agronegócio, ao dispor da terra pela via da estratégia economicista - e gerar problemas ambientais face ao modo pelo qual a terra é usada - desdobra-se na injustiça ambiental consoante a injustiça social. (Souza \& Chaveiro, 2018, p. 2-3).

Assim, é notório que os problemas que decorrem das relações ambientais e delas associados, tais como o agronegócio e a regularização da demarcação das terras quilombolas e indígenas, estão intrinsecamente ligados às questões de relação de poder, de ordem política e econômica de um país e seus representantes, o que nos leva a refletir sobre a grande dívida social que o Estado brasileiro tem com as comunidades tradicionais, o que influencia na sua própria sobrevivência, no direito ao consumo material, na justiça social, no uso dos bens comuns, na igualdade de oportunidades, dentre outros (Souza \& Chaveiro, 2018), o que faz refletir sobre as palavras de Feijão Querentin (2019):

Aqui não tem ganho: por exemplo, uma época dessa, se você não trabalhar na roça, você não faz nada, fica zanzando feito louco, preocupado com o nosso ganha-pão. E outra: nosso trabalho, às vezes, não recompensa financeiramente; você não consegue vender nem o milho. Não compensa, pois você passa quase um ano todo: primeiro na broca, depois limpa, depois planta, apanha feijão, quebra de milho... Ave, Maria! Todo um processo demorado demais, aí, quando é no final, como agora, os caras querem pagar $\mathrm{R} \$ 25,00$ no saco de milho; não compensa, na minha opinião. Um saco de feijão, que é R \$ 150,00, não compensa também, muito melhor você guardar e comer... Já com a semente do governo a produção é mais rápida, porque tem muito veneno, mas, se você for comprar, ela é cara para caramba... e o milho do governo o quilo é R $\$ 4.00$, mas, se você for vender o nosso, o cabra não quer pagar nem $\mathrm{R} \$ 1,00 \ldots$ e o milho do governo vem até com o corante que eles colocam e dizem que é para conservar o milho... o nosso não tem nada disso, a nossa semente é natural.

Percebe-se, assim, que as iniciativas do governo seriam mais para alimentar a indústria de agrotóxico, a exploração territorial, o aumento da lucratividade das grandes empresas, ficando as ações inerentes ao cultivo de sementes crioulas e 

forma de luta e resistência pela identidade sociocultural quilombola na comunidade Sítio Veiga em Quixadá-CE...

seu potencial sustentável sem o apoio necessário do governo, fazendo refletir que, quando ocorre alguma ação, é de maneira fragmentada, assistencialista e muito pontual.

A ausência do apoio necessário às comunidades quilombolas por parte do governo tem impactado direta e/ou indiretamente nas atividades naturais do campo, ou seja, o uso de agrotóxicos por algumas pessoas - que acabam por contaminar os solos e a originalidade das sementes crioulas com essa prática, seja pela terra contaminada, seja pelo ar que circula na atmosfera - pode contaminar as plantações, como afirma Milho Amarelo (2019):

Eu não uso veneno, nunca fiz essa experiência, mas tem gente usando escondido... $\mathrm{O}$ pessoal fala que parece que cresce mais rápido a plantação, faz com que o feijão e principalmente o milho cresçam mais ligeiro e tenham mais produção, aí a vantagem para muitos usarem o veneno, até porque, quando não se planta no veneno, você dá de duas a três limpas no roçado, e no veneno o mato já está grande, e você bota o veneno e mata todo o mato, e, quando você vai dar uma limpa, o legume já está quase todo pronto, no ponto de produção, aí só com uma limpa a pessoa tira... aí tem gente que planta o milho no veneno e não limpa de jeito nenhum, plantou ali, colocou o veneno e só vai lá mesmo para colher, por isso tem gente que não aceita botar veneno na propriedade, porque contamina a água; escorre e contamina os açudes... Quando coloca veneno, geralmente você só planta e coloca o veneno ali; pronto, você só vai mesmo para colher o legume, não tem aquele trabalho de plantar e, com vinte ou trinta dias depois, você tem que entrar para dentro para limpar todo o mato. Se não botar o veneno, é mais demorado e dá mais trabalho, porque temos que capinar todo o mato, são mais homens para fazer esse serviço para limpar o mato, enquanto com veneno uma única pessoa faz o serviço... Com o natural se torna mais demorado e caro para a gente. Mas dizem que o veneno causa mal à saúde, causa até o câncer. Onde você bota veneno demora a nascer o mato; para quem tem criação de animal, gado, por exemplo, demora muito a sair a forragem dos bichos e, em muitas terras aqui, o interesse é mais nas forragens para os animais, aí, se você coloca veneno, demora mais ainda a forragem, demora a sair outro mato para se tornar forragem para os bichos; quando nasce, se torna mais fraca a forragem, por isso que tem dono de terra que não aceita colocar veneno de jeito nenhum por causa disso, por causa dos alimentos dos bichos, que ficam comprometidos.

A população quilombola do Sítio Veiga enfrenta ainda outro grande desafio: a luta pela posse de suas terras, isto é, a desapropriação. Tal situação vem ocasionando enormes perdas ao longo dos anos, tanto para as famílias como para as variedades de sementes crioulas, posto que, como ainda não têm a posse legal das terras, continuam plantando sob o sistema opressor de renda, ou seja, parte do que produzem fica para o dono do terreno, embora estas terras estejam dentro do 
próprio território que já foi demarcado e legitimado como quilombola pela Fundação Palmares, todavia, como ainda não foi feita a desapropriação dessas terras, ficam sujeitos a deixar parte de seus produtos - inclusive a forragem, que poderia alimentar seus animais - para os "donos" das terras usufruírem desses recursos, tirando proveito deles para alimentarem os seus animais sem que tenham contribuído nesse processo.

É de cortar o coração das famílias quilombolas ver seu suor, seu sangue sendo esmagado, pisoteado, alimentando os animais de quem não moveu sequer uma palha, para ver sua fartura ter outro fim. Quando os animais são colocados dentro dos roçados para comer, junto com a forragem devoram também sementes, que em breve alimentariam pessoas, vidas, seriam também a continuidade de seu ciclo natural, de um ritual (colher, desbulhar, catar, guardar e plantar). Processo lindo, de construção coletiva, do fazer, do produzir coletivo, contribuindo cada vez mais para o fortalecimento da organização social dentro e fora do quilombo. (Fava Espírito Santo, 2019).

A desocupação das terras fora do período adequado traz muitos prejuízos aos(às) quilombolas, pois perdem quase toda a produção de favas, motivo por que muitos(as) estão deixando de plantar as favas balinha, espírito santo e manteiga; estas são as que ainda existem, resistindo à opressão de mais de um século. Estas poderiam alimentar as famílias atuais e as futuras gerações se seu ciclo de vida fosse respeitado.

A colheita antecipada traz impacto negativo na alimentação dos(as) quilombolas, danos psicológicos e perda de muitas sementes crioulas. Todos esses mecanismos são utilizados como forma de desanimar e afastar essas famílias da produção de seus próprios alimentos e de suas formas de organicidade.

$\mathrm{O}$ rompimento desse ritual acarreta danos aos âmbitos social, cultural, político e econômico, pois mexe com a estrutura não somente dos(as) quilombolas do Veiga, mas de toda a sociedade, interferindo na cadeia alimentar e sucessivamente na alimentação e nutrição das pessoas. Cabe destacar que os animais dos donos dos terrenos, quando são colocados nos roçados dos(as) quilombolas, devoram mais de $30 \%$ da produção de fava que ainda está em pleno processo de florada e amadurecimento das sementes, visto que demoram mais tempo para produzirem e também para serem colhidas.

Diante do exposto, faz-se necessário colocar as comunidades tradicionais quilombolas, dentre estas a comunidade Sítio Veiga, nas ações de incentivo e apoio ao desenvolvimento agrícola, respeitandose a singularidade desses sujeitos sociais e os conhecimentos tradicionais herdados 
por seus ancestrais. Essa ação deverá seguir o reconhecimento e a valorização do potencial de suas sementes crioulas, de sua força produtiva no campo e da produção por eles(as) realizada; ação que deve ser somada à resolução das demandas existentes, tal como a legitimação da posse das terras, o controle das indústrias do veneno nas plantações e $\mathrm{o}$ apoio e incentivo a esses sujeitos sociais a permanecerem em seus territórios, dando continuidade às suas tradições nas atividades agrícolas e socioculturais associadas.

\section{Considerações}

No território quilombola do Sítio Veiga, as formas de organização coletiva em torno do cultivo de sementes crioulas são de extrema importância para a preservação da identidade sociocultural quilombola, da memória de seus ancestrais e da existência das futuras gerações.

As sementes crioulas não são plantadas sob o jugo da agricultura industrial, na perspectiva globalizada do agronegócio, mas de acordo com o conhecimento absorvido por seus ancestrais, passado entre gerações, garantindo a alimentação e a manutenção das famílias e de seus animais. As atividades permitem uma maior aproximação e solidariedade entre as pessoas de seu quilombo e de outros quilombos, o que as leva à troca de conhecimentos, resgatando a memória de seus ancestrais e de algumas espécies perdidas.

Todavia, apesar da relevância da organização coletiva das sementes crioulas, a desvalorização e a falta de apoio a essas ações por parte do poder público estabelecem diversas lacunas à autonomia dessas famílias, dado que dependem das terras de terceiros para plantarem suas sementes.

As comunidades quilombolas ainda são colocadas em último plano na agenda do governo no campo das políticas públicas, sobretudo quando comparadas ao agronegócio, que tem apoio prioritário, ferindo os próprios preceitos constitucionais de as famílias quilombolas continuarem cultivando suas sementes crioulas de forma natural.

A não legitimação das terras a essas famílias faz com que se tornem vulneráveis à própria contaminação de suas sementes nativas. A plantação dessas sementes em terras de terceiros, sem um rigoroso controle do veneno, prejudica a originalidade das sementes crioulas e os conhecimentos perpassados por seus ancestrais em preservar essas espécies às próximas gerações, o que compromete seu futuro e o direito de essas sementes 

forma de luta e resistência pela identidade sociocultural quilombola na comunidade Sítio Veiga em Quixadá-CE...

continuarem existindo. Isso suscita a reflexão de que grande parte de suas demandas seria resolvida com a posse da terra e do controle da produtividade, o que atualmente se configura apenas como atividade de subsistência humana, não dando para suprir todas as necessidades das famílias quilombolas do Sítio Veiga.

A implantação da casa de semente se destacou como uma das maiores conquistas no processo de organização coletiva, visto que fortaleceu a cultura das sementes até então presente nos seus hábitos cotidianos, da relação com a agricultura e com o manejo das sementes, despertando uma consciência maior para a preservação ambiental, não se deixando influenciar pelo uso de agrotóxicos nas plantações, em razão do enorme apelo existente destes na distribuição das sementes do governo repassadas anualmente para o agricultor.

Diante do exposto, faz-se necessário revermos os processos históricos que situam a população quilombola e suas formas de organização em torno do cultivo de suas sementes, pois, ao quebrarmos os estereótipos sobre esses sujeitos sociais e suas formas peculiares de ser e viver, de se organizar coletivamente, poderemos criar imagens mais positivas e, a partir daí, traçar caminhos mais dignos e capazes de lhes assegurar o direito de terem garantidos seus territórios, suas terras, de plantarem suas sementes com mais autonomia e independência.

\section{Referências}

Bâ Hampâté, A. (2010). Tradição viva. In Ki-Zerbo, L. (Org.). História geral da África I: metodologia e pré-história da África (pp. 167-212). Brasília: Unesco.

Barbosa, M. M., Alenar, F. A. G., Ziegler, H. R. S., \& Ziegler, S. E. S. (2013). Educação no campo e agroecologia: alternativas para o resgate das sementes crioulas. In Matos, K. S. A. L. (Org.). Educação ambiental e sustentabilidade IV (pp. 374-387). Fortaleza: UFC.

Brasil. (1988). Constituição de 1988. Constituição da República Federativa do Brasil. Diário Oficial [da] República Federativa do Brasil, Poder Executivo, Brasília, DF, 5 out.

Brasil. (2012). Resolução no 466, de 12 de dezembro de 2012. Diretrizes e normas regulamentadoras de pesquisas em seres humanos. Diário Oficial [da] República Federativa do Brasil, Poder Executivo, Brasília, DF, 13 dez.

Carvalho, H. M. (2003). (Org.). Sementes, patrimônio do povo a serviço da humanidade. São Paulo: Expressão Popular.

Cunha, F. I., Silva, A. M. E., \& Vasconcelos, J. G. (2019). Casa de sementes Pai Xigano: um olhar para os saberes ancestrais do cultivo de sementes crioulas no quilombo Sítio Veiga, Quixadá-CE. Revista Cocar, 13(27), 903923.

Diário do Nordeste. (2017). Quilombos: resistência para vencer invisibilidade histórica. 20 nov. Recuperado de: https://diariodonordeste.verdesmares.com. 

forma de luta e resistência pela identidade sociocultural quilombola na comunidade Sítio Veiga em Quixadá-CE...

br/editorias/metro/quilombos-resistenciapara-vencer-invisibilidade-historica-

\section{$\underline{1.1853301}$}

Diegues, A. C. S., Arruda, R. S. V., Silva, V. C. F., Figols, F. A. B., \& Andrade, D. (1999). Saber tradicional, ciência e biodiversidade. In Diegues, A. C. S. (Org.). Biodiversidade e comunidades tradicionais no Brasil (pp. 30-35). São Paulo: USP.

Domingos, L. T. (2011). A visão africana em relação à natureza. Revista Brasileira de História das Religiões, 3(9), 3-9.

Figueiredo, G. P., Barbosa, M. M., \& Pinheiro, R. S. (2013). Agroecologia integrada à educação ambiental: ferramentas para uma melhor convivência da população com o semiárido. In Matos, K. S. A. L. (Org.). Educação ambiental e sustentabilidade IV (pp. 360-373). Fortaleza: UFC.

Leite, I. B. (2000). Os quilombos no Brasil: questões conceituais e normativas. Etnografia, 4(2), 333-354.

López, G. L. (1999). O método etnográfico como um paradigma científico e sua aplicação na pesquisa. Textura, 1(2), 4550 .

Minayo, M. C. S. (2002). O desafio do conhecimento: pesquisa qualitativa em saúde. São Paulo: Hucitec.

Monteiro, K. S., \& Garcia, M. F. (2010). Territorialização quilombola: o caso da comunidade negra de Gurugi, Paraíba. Revista Pegada, 11(2), 148-170. https://doi.org/10.33026/peg.v11i2.1310

Monteiro, S. (2004). Desigualdade em saúde, raça e etnicidade: questões e desafios. In Monteiro, S., \& Sansone, O. (Org.). Etnicidade na América Latina: um debate sobre raça, saúde e direitos reprodutivos (pp. 45-56). Rio de Janeiro: Fiocruz. $\underline{\text { https://doi.org/10.7476/9788575416150.00 }}$ $\underline{03}$

Munanga, K. (1996). Origem e histórico do quilombo na África. Revista USP, (28), 5663. https://doi.org/10.11606/issn.23169036.v0i28p56-63

O Candeeiro. (2016). Casas de Sementes Pai Xigano: autonomia e liderança negra no semiárido. Boletin Informativo do Programa uma Terra e Duas Águas, Quixadá, Ceará, p. 1.

Revista Carta Capital. (2019). Manifesto. Recuperado de: https://www.cartacapital.com.br/politica/bo 1sonaro-libera-queimadas-paraagronegocio-fora-da-amazonia/

Silva, S. R., \& Nascimento, L. K. (2012). Negros e territórios quilombolas no Brasil. Cadernos Cedem, 3(1), 23-37. https://doi.org/10.36311/22360247.2012.v3n1.p23-37

Souza, L. B., \& Chaveiro, E. F. (2019). Território, ambiente e modos de vida: conflitos entre o agronegócio e a comunidade quilombola de Morro de São João, Tocantins. Sociedade \& Natureza, $31, \quad 1-25$. https://doi.org/10.14393/SNv31n1-2019-42482

Trindade, C. C. (2006). Sementes crioulas e transgênicos, uma reflexão sobre sua relação com as comunidades tradicionais. In Anais do Congresso Nacional do Conpedi (pp. 1-15), Manaus, AM.

\section{Fontes orais}

Amarelo, Milho. Entrevistadora: Fernanda Ielpo da Cunha. Comunidade Quilombola de Sítio Veiga, Quixadá-CE, 15 ago. 2019, mp2, 30 min. Disponível no acervo pessoal dos autores.

Balinha, Feijão. Entrevistadora: Fernanda Ielpo da Cunha. Comunidade Quilombola 
de Sítio Veiga, Quixadá-CE, 15 ago. 2019, mp2, 43 min. Disponível no acervo pessoal dos autores.

Espiríto Santo, Fava. Entrevistadora: Fernanda Ielpo da Cunha. Comunidade Quilombola de Sítio Veiga, Quixadá-CE, 08 ago. 2019, mp3, 57 min. Disponível no acervo pessoal dos autores.

Querentin, Feijão. Entrevistadora: Fernanda Ielpo da Cunha. Comunidade Quilombola de Sítio Veiga, Quixadá-CE, 15 ago. 2019, mp3, 13 min. Disponível no acervo pessoal dos autores.

\footnotetext{
${ }^{1}$ No Brasil, a palavra "quilombo" tem sua origem nos povos de língua bantu (Kilombo), especificamente dos grupos luanda, ovimbundu, mbundu, kongo, imbangola, dentre outros, cujos territórios se dividem entre Angola e Zaire. Esse termo envolve diversas simbologias e expressões linguísticas (Munanga, 1996).
}

2 "Órgão com responsabilidade de emitir o certificado de autorreconhecimento do povo quilombola. Grupos étnicos com predominância na população negra rural ou urbana se autodefinem a partir das relações com a terra, parentesco e práticas culturais de antepassados africanos" (Diário do Nordeste, 2012, p. 1).

3 Francisco Ribeiro Bessa, conhecido como Chiquinho Ribeiro ou Pai Xigano, e Maria Fernandes da Silva, conhecida como Mãe Veia, foram o casal fundador da comunidade Sítio Veiga, onde residem atualmente 39 famílias. Segundo os registros históricos, em 1906 esse casal e a família migraram de Pau dos Ferros, município do Rio Grande do Norte, para a região da Serra do Evaristo, em Quixadá, no Ceará, onde fixaram raízes e iniciaram a história da comunidade na localidade onde hoje está o Sítio Veiga. Ao longo do tempo, a família Ribeiro se misturou, por meio de trocas matrimoniais, com a família Eugênio, do distrito de Dom Maurício, em Quixadá-CE. Em 2010, a comunidade iniciou a construção de uma casa de sementes, conhecida carinhosamente como casa de semente Pai Xigano, nome escolhido pelos moradores, o qual remete à memória e à ancestralidade de Francisco Ribeiro Bessa, o primeiro a trazer a semente crioula a fecundar o então quilombo, juntamente com sua esposa, Maria Fernandes, e seus filhos (Cunha et al., 2019). iv Organização não governamental sem fins lucrativos fundada em 1974 no município de Fortaleza-CE. A organização atua diretamente em municípios do semiárido cearense, desenvolvendo atividades para a agroecologia e a agricultura familiar.

${ }^{v} \mathrm{O}$ golpe mencionado pelo(a) entrevistado(a) faz referência ao impeachment da presidenta Dilma Rousseff, ocorrido em 31 de agosto de 2016.

${ }^{6}$ Dança em homenagem ao santo português Gonçalo. No quilombo Sítio Veiga, a dança de São Gonçalo é uma expressão cultural repassada através das gerações para os(as) descendentes da comunidade. Atualmente a dança é animada pelo neto de Chiquinho Ribeiro e Maria Ribeiro, seu Joaquim Ferreira da Silva (Joaquim Roseno).

Informações do artigo / Article Information

Recebido em : 14/05/2020

Aprovado em: 01/08/2020

Publicado em: 27/11/2020

Received on May 18th, 2020

Accepted on August 01st, 2020

Published on November, 27th, 2020

Contribuições no artigo: Os autores foram os responsáveis por todas as etapas e resultados da pesquisa, a saber: elaboração, análise e interpretação dos dados; escrita e revisão do conteúdo do manuscrito e; aprovação da versão final publicada.

Author Contributions: The author were responsible for the designing, delineating, analyzing and interpreting the data, production of the manuscript, critical revision of the content and approval of the final version published.

Conflitos de interesse: Os autores declararam não haver nenhum conflito de interesse referente a este artigo.

Conflict of Interest: None reported.

Orcid

Fernanda lelpo da Cunha

D http://orcid.org/0000-0002-4429-5555

Luís Tomás Domingos

(iD)

http://orcid.org/0000-0002-0062-6834

Ana Maria Eugenio da Silva

http://orcid.org/0000-0002-6121-7882

José Gerardo Vasconcelos

http://orcid.org/0000-0003-0559-2642 
Cunha, F. I., Domingos, L. T., Silva, A. M. E., \& Vasconcelos, J. G. (2020). Organizaçãa coletiva e sementes crioulas: uma forma de luta e resistência pela identidade sociocultural quilombola na comunidade Sitio Veiga em Quixadá-CE...

\section{Como citar este artigo / How to cite this article}

\section{APA}

Cunha, F. I., Domingos, L. T., Silva, A. M. E., \& Vasconcelos, J. G. (2020). Organização coletiva e sementes crioulas: uma forma de luta e resistência pela identidade sociocultural quilombola na comunidade Sítio Veiga em Quixadá-CE. Rev. Bras. Educ. Camp., 5, e9219. http://dx.doi.org/10.20873/uft.rbec.e9219

\section{ABNT}

CUNHA, F. I.; DOMINGOS, L. T.; SILVA, A. M. E.; VASCONCELOS, J. G. Organização coletiva e sementes crioulas: uma forma de luta e resistência pela identidade sociocultural quilombola na comunidade Sítio Veiga em Quixadá-CE. Rev. Bras. Educ. Camp., Tocantinópolis, v. 5, e9219, 2020. http://dx.doi.org/10.20873/uft.rbec.e9219 